\title{
Epidemiology, Quality of Life, and Costs Associated with Hypoglycemia in Patients with Diabetes in Spain: A Systematic Literature Review
}

\author{
Mercedes Núñez (D) - Silvia Díaz · Tatiana Dilla · Jesús Reviriego • \\ Antonio Pérez
}

Received: November 6, 2018 / Published online: January 19, 2019

(c) The Author(s) 2019

\begin{abstract}
Objective: To assess the burden of hypoglycemia in patients with diabetes mellitus (DM) in Spain, including epidemiological data and information relating to healthcare resource utilization (HRU) and costs, and patients' quality of life (QoL).

Methods: A systematic literature review (SLR) was conducted to identify studies that included original information on epidemiology, HRU and costs, and/or QoL associated with hypoglycemia in patients with DM in Spain, published in either Spanish or English, between January 2007 and April 2017.

Results: Fifteen articles, involving 14 studies, were identified in the SLR and included in the analysis. The estimated rate of severe hypoglycemia (SH) events per patient per year ranged from 0.90 to 1.50 in patients with type $1 \mathrm{DM}$ (T1DM) and from 0.30 to 0.63 in patients with type $2 \mathrm{DM}$ (T2DM). The data on HRU differed
\end{abstract}

Enhanced Digital Features To view enhanced digital features for this article go to https://doi.org/10.6084/ m9.figshare.7547183.

M. Núñez (ه) · S. Díaz · T. Dilla · J. Reviriego

Eli Lilly and Company, Madrid, Spain

e-mail: nunez_mercedes@lilly.com

\section{A. Pérez}

Department of Endocrinology and Nutrition, Hospital de la Santa Creu I Sant Pau, Barcelona, Spain extensively between studies, making it difficult to draw a conclusion. Total costs per SH event ranged from $€ 409.97$ in patients with T1DM to $€ 713.10$ in patients with DM. Work absence was reported in $11.80-18 \%$ of the working patients. Further, patients who experienced hypoglycemic events expressed a higher fear and had a poorer QoL than those who did not report these events.

Conclusion: Although the data included in the SLR were difficult to synthesize due to heterogeneity of the study designs and patient characteristics in the 14 studies, our search identified a high burden associated with hypoglycemic events in terms of HRU and costs, and patients' QoL. Further research is recommended to reach a consensus on hypoglycemia definition and study design to provide robust evidence on the burden of hypoglycemia and to accurately weigh the impact of this acute complication in Spain.

Funding: Eli Lilly and Company.

Keywords: Diabetes mellitus; Hypoglycemia; Observational studies; Spain; Systematic literature review

\section{INTRODUCTION}

Diabetes mellitus (DM) is a group of metabolic disorders characterized by chronic hyperglycemia that develops because of insufficient 
insulin secretion, reduced responsiveness to insulin, or both [1]. The eighth edition of the International Diabetes Federation (IDF) 2017 Diabetes Atlas, a global reference report, estimates that 424.90 million $(8.80 \%)$ adults were affected by DM in 2017 globally. This number is estimated to increase to 628.60 million $(9.90 \%)$ by 2045 [2]. A survey was conducted in 2009-2010 with the aim to quantify the prevalence of DM in Spain [3]; at that time it was estimated that DM affected $13.80 \%$ of the population and that these numbers would likely increase given estimated global figures [4]. In addition, global expenditure attributable to the care of DM patients has become an enormous economic burden on healthcare services, reaching US $\$ 727$ billion in 2017 [2]. Projections in Spain reveal a comparable growth in upcoming years in the expenditure of the Spanish healthcare system for the care of DM patients [5-7]. Moreover, these predictions may worsen since the available estimations are usually described for patients who have been diagnosed with diabetes and do take into account the significant number of undiagnosed diabetic cases [8]. The most distressing consequence of DM appears to be its late complications. However, hypoglycemia, one of the acute complications of DM [9], also significantly impacts disease management, patients' quality of life (QoL), and costs $[8,10]$.

Insulin and a number of other glucose-lowering drugs may cause hypoglycemia. According to the recommendations of the International Hypoglycemia Study Group [11], a hypoglycemia alert value of $\leq 70 \mathrm{mg} / \mathrm{dL}(3.90 \mathrm{mmol} /$ $\mathrm{L})$ is often related to symptomatic hypoglycemia and can be an considered important value for therapeutic dose adjustment of glucose-lowering drugs for patients in clinical care. Further, a blood glucose level of $<54 \mathrm{mg} / \mathrm{dL}$ $(3.00 \mathrm{mmol} / \mathrm{L})$ is considered sufficiently low to indicate clinically significant hypoglycemia. Severe hypoglycemia ( $\mathrm{SH}$ ) is defined as severe cognitive impairment requiring assistance from another person for recovery [11].

Symptoms attributed to hypoglycemia are categorized as neurogenic (autonomic) or neuroglycopenic [12]. Depending on its severity or duration, hypoglycemia can lead to seizure or coma, and ultimately death. Recent post hoc analyses of the ACCORD, ADVANCE and DEVOTE 3 trials, all of which examined the outcomes of intensive glycemic control, revealed a high association between $\mathrm{SH}$ and significantly higher rates of death [13-15]. For all of these reasons, these SH episodes are associated with considerable costs, both to the individual and to the healthcare system [16], and they also contribute to significant reductions in QoL in patients with DM and to a fear of hypoglycemia [17].

Despite the importance of being aware of this information for the correct management of hypoglycemia, none of the studies to date in the Spanish landscape have collected integrated data related to the burden of hypoglycemia. The aim of this systematic literature review (SLR) was to review available data in order to assess the burden of hypoglycemia in terms of its epidemiology, healthcare resource utilization (HRU), costs, and QoL in patients with DM in Spain.

\section{METHODS}

This SLR was planned, conducted, and reported according to the Preferred Reporting Items for Systematic Reviews and Meta-Analyses (PRISMA) guidelines. Two independent reviewers screened each retrieved record to identify potentially relevant articles for the full-publication review. A third senior researcher arbitrated in case of any doubt on eligibility or disagreement between the two primary reviewers.

The SLR included observational studies conducted in Spain published between January 2007 and April 2017 that involved patients with any type of diabetes and which present original information on epidemiology, costs, HRU and/ or QoL of patients with hypoglycemia. Both English and Spanish language publications were included in the search. Articles not presenting original data (such as SLR, reviews, letters to the editor, etc.), clinical trials, cost-effectiveness models, and abstracts or congress communications, and those studies that present 
hypoglycemia data associated with a specific drug or intervention were not included in our SLR.

Articles that reported costs were actualized to the corresponding value in euros in 2016 using the CCEMG-EPPI-Centre Cost Converter tool in order to enable meaningful comparisons between costs [18].

A comprehensive search strategy was developed for the databases: Ovid (Embase + MEDLINE) and MEDES (Spanish bibliographic database). The corresponding search strategies used are presented as follows:

- MEDES (https://www.medes.com/Public/ Home.aspx): (((hipoglucem*[título] OR hipoglucem*[resumen] OR hipoglucem*[palabras_clave]) AND ((epidemiologia[título] OR epidemiologia[resumen] OR epidemiologia[palabras_clave]) OR (incidencia[título] OR incidencia[resumen] OR incidencia[palabras_clave]) OR (prevalencia[título] OR prevalencia[resumen] OR prevalencia[palabras_clave]) OR (calidad[título] OR calidad[resumen] OR calidad[palabras_clave]) OR (vida[título] OR vida[resumen] OR vida[palabras_clave]) OR (carga[título] OR carga[resumen] OR carga[palabras_clave]) OR (coste*[título] OR coste*[resumen] OR coste*[palabras_clave]) OR (econom*[título] OR econom*[resumen] OR econom*[palabras_clave])))) AND (2007[año_publicación]: 2017[año_publicación])

- Ovid (http://link.am.lilly.com/sites/link/ DataSources/Pages/EMBASE.aspx): Database: Embase $<1974-2017$ April 17> ; Ovid MEDLINE(R) <1946 to April Week 1 2017>.

1. exp *nocturnal hypoglycemia/or exp *hypoglycemia/or exp *insulin hypoglycemia/(41,684)

2. Item 1 or hypoglyc ${ }^{\star}$.ti. $(51,796)$

3. (spain OR espagne OR espana OR spain OR espagne OR espana OR osasunbide* OR osakidetza OR insalud OR sergas OR catalunya OR catalonia OR catalogne OR cataluna OR catala OR barcelon* OR tarragona OR lleida OR lerida OR girona OR gerona OR sabadell OR hospitalet OR l'hospitalet OR valencia* OR castello* OR alacant OR alicant* OR murcia* OR andalu* $^{*}$ OR sevill ${ }^{*}$ OR granad* OR huelva OR almeria OR cadiz OR jaen OR malaga OR [cORdoba not argentin*] OR extremadura OR caceres OR badajoz OR madrid OR castilla OR salamanca OR zamORa OR valladolid OR segovia OR sORia OR palencia OR avila OR burgos OR [leon not ffrance OR clermont OR rennes OR lyon OR USA OR mexic*\}] OR galicia OR gallego OR compostela OR vigo OR cORuna OR ferrol OR ORense OR ourense OR pontevedra OR oviedo OR gijon OR asturia* OR cantabr* OR santander OR vasco OR euskadi OR basque OR bilbao OR bilbo OR donosti* OR san sebastian OR vizcaya OR biscaia OR guipuzcoa OR gipuzkoa OR alava OR araba OR vitORia OR gazteiz OR navarr* OR nafarrona OR pamplona OR iruna OR irunea OR aragon* OR zaragoza OR teruel OR huesca OR mancha OR ciudad real OR albacete OR cuenca OR [toledo not \{ohio OR us OR usa OR OH\}] OR (guadalajara not mexic*) OR balear* OR mallORca OR menORca OR ibiza OR eivissa OR palmas OR lanzarote OR canari* OR tenerife).mp. $(223,672)$

4. Items 2 and 3 (140)

5. $\quad$ Limit 4 to year $=$ "2007-2017" (103)

6. 5 not clinical trial/(93)

7. Limit 6 to (conference abstract or conference paper or conference proceeding or "conference review" or editorial) [Limit not valid in Ovid MEDLINE(R); records were retained] (18)

8. 6 not 7 (75)

The reviewers collected the following information from each article selected in the SLR.

1. Variables which described the main methodological characteristics, including the study design, information on followup and data collection, sample inclusion criteria, type of DM, number of patients in the study, mean age of the patients, mean duration of the DM, time frame to record hypoglycemia, severity of the hypoglycemic event reported, and healthcare system setting.

2. Epidemiology variables, comprising frequency of SH and non-severe hypoglycemia (NSH), hypoglycemic events per year for $\mathrm{SH}$ 


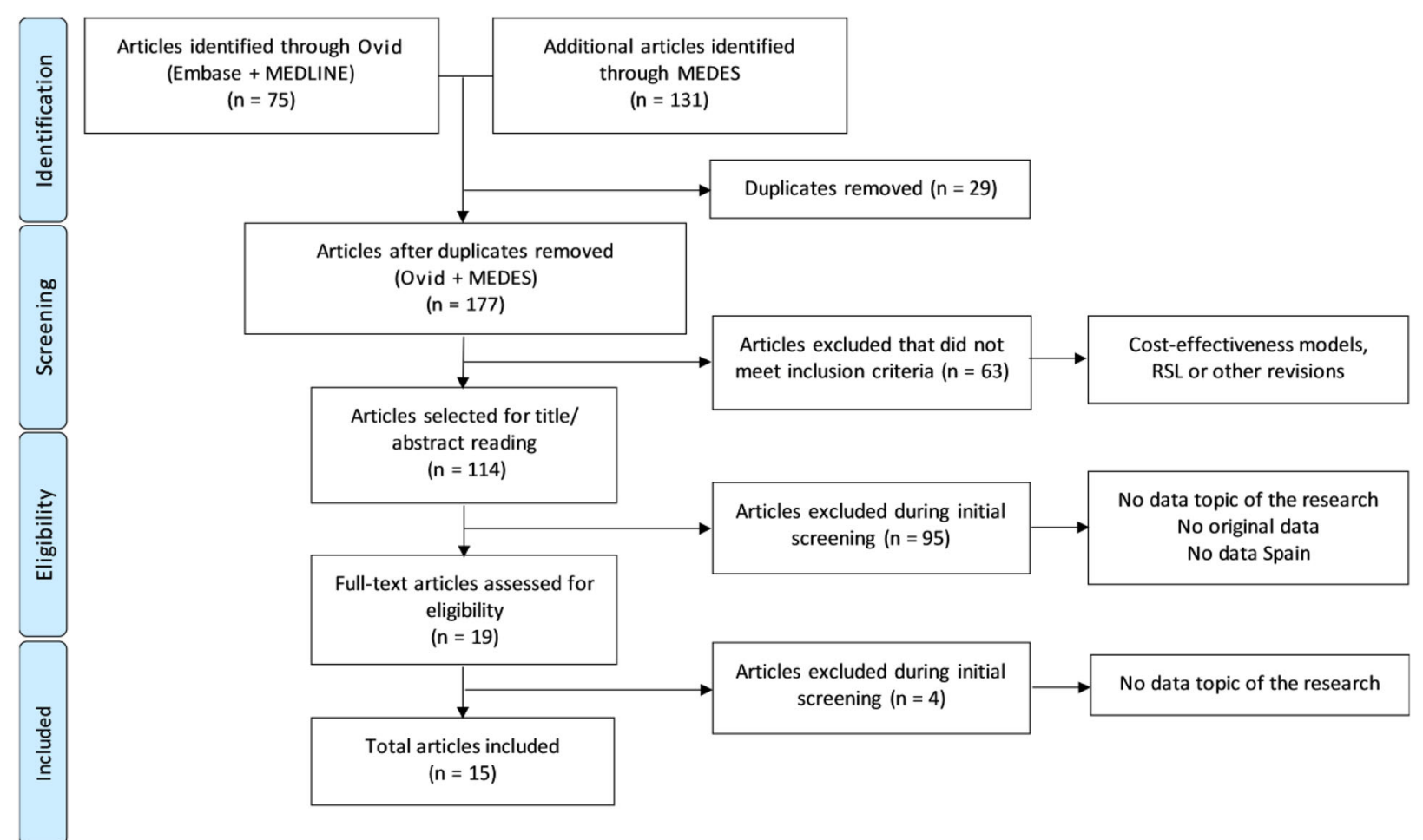

Fig. 1 PRISMA (Preferred Reporting Items for Systematic Reviews and Meta-Analyses) flow diagram

and $\mathrm{NSH}$, and frequency of nocturnal hypoglycemia.

3. HRU and costs' variables, involving HRU per hypoglycemic event, costs related to hypoglycemia (direct and indirect costs), total costs, and information on impact at work.

4. QoL variables, including questionnaires used and main results, i.e., the scores for the hypoglycemic population versus the defined control population in each article and statistical significance of the comparison.

Ethical approval was not required since this article is based on previously conducted studies and did not involve experiments with animals or humans performed by any of the authors.

\section{RESULTS}

The search strategy identified 206 references (75 from Ovid and 131 from MEDES), of which 15 publications involving 14 studies were included in the analysis after the systematic review process (Fig. 1).

\section{Description of the Selected Studies in the SLR}

Of the 15 publications (14 studies) included in the SLR, six studies focused exclusively on data from patients with type 2 DM (T2DM) [19-24] and five studies reported combined data from patients with either type 1 DM (T1DM) or T2DM [25-30]. Only two studies highlighted data exclusively for patients with T1DM $[31,32]$, and one study reported neonatal hypoglycemia [33]. All of the studies collected data retrospectively employing a cross-sectional study design, with the exception of one study that used a longitudinal study design [22]. The majority of the studies reported the management of hypoglycemia events at either hospitals or a primary care setting; the exceptions were two studies that presented data from specialized care and emergency service settings [24, 29] and 
two studies that did not report the study settings [26-28].

The number of patients in the studies ranged widely, from 100 in a study determining the costs of SH in patients with T1DM [31] to $5,447,725$ clinical records from the basic minimum data set (BMDS) registry of the Spanish National Health System that includes general information on patients with DM [30]. The mean age of patients with T1DM ranged from 33.20 to 33.90 years, while studies reporting data for patients with T2DM included patient populations with a mean age ranging from 64 to 79.70 years. However, a wide-ranging mean age was observed in studies presenting data of patients with either T1DM or T2DM, from 39.90 to 70.20 years. The mean duration of the disease in patients with T1DM and T2DM ranged from 16.50 to 18.50 and from 8.40 to 20 years, respectively. One of the studies included in the SLR focused exclusively on neonatal hypoglycemia; the aim of this study was to determine whether an association exists between maternal pre-pregnancy body mass index category and the occurrence of neonatal hypoglycemia among infants born to women with gestational DM [33].

\section{Epidemiology of Hypoglycemia}

Table 1 presents the epidemiology data on hypoglycemia detailed in the studies selected for inclusion in this SLR (15 publications).

\section{Type 1 Diabetes Mellitus}

The average number of hypoglycemia episodes per patient was reported in three studies. Reviriego et al. recorded a mean of $2.99 \mathrm{SH}$ events per patient per 2-year period, with a higher number of overall hypoglycemic episodes (54.40 events/patient/2 years) [31]. Orozco-Beltrán et al. reported an annual frequency of 0.90 events for SH and $1.70 \mathrm{NSH}$ events per week, or an annual frequency of 88 NSH events [26]. Carral et al. reported a mean of 7.40 events ( $\mathrm{SH}$ or $\mathrm{NSH}$ ) per patient in 1 month [32].

\section{Type 2 Diabetes Mellitus}

The frequency of hypoglycemic events was described in eight studies. An incidence of 1.82 episodes per 10,000 patients per year for $\mathrm{SH}$ was reported by Lindner et al. [25]. Orozco-Beltrán et al. reported an annual frequency of 0.30-0.40 events per year for SH, and 18.30-42.10 events per year for NSH [26]. Three studies described the incidence of $\mathrm{SH}$ as the percentage of patients who experienced an episode in 1 year, namely, 6.80\% [20], 1.90\% [21] and 0.56\% [23], with the setting of the first two studies being primary care and that of the third study being the hospital.

In the study of Pérez et al., 93.20\% of patients reported NSH or no hypoglycemia in a 1-year period [20], while Depablos-Velasco et al. reported that $9.60 \%$ of patients had NSH in the previous month [21]. A small number of studies did not differentiate between $\mathrm{SH}$ and NSH in these patients. Durán-Alonso et al. reported that $15.70 \%$ of patients in nursing homes experienced symptomatic hypoglycemia [19]. In a 2-year study by Sicras-Mainar et al., 37.70\% of patients reported at least an episode of hypoglycemia [22], and Jódar-Gimeno et al. reported that $45 \%$ of patients experienced hypoglycemia in the previous 6 months [24].

\section{Nocturnal Hypoglycemia}

The epidemiologic data for nocturnal hypoglycemia were analyzed from three studies. Barranco et al. employed Public Company for Health Emergencies Service (EPES; Andalusian emergency service) data and noted that there were 2297 nocturnal SH episodes in a 1-year, which translated into 0.34 episodes per hour that required the assistance of emergency services [29]. Brod et al. explored the impact of nocturnal NSH events in similar patients who experienced an event in the past month and reported a mean of 21.60 nocturnal NSH events in 1 year [27]. In terms of nocturnal hypoglycemia according to the type of diabetes, the proportion of NSH events occurring at night was $26 \%$ in $\mathrm{T} 1 \mathrm{DM}$ patients and $30-32 \%$ in T2DM patients recorded in the previous week [26]. 


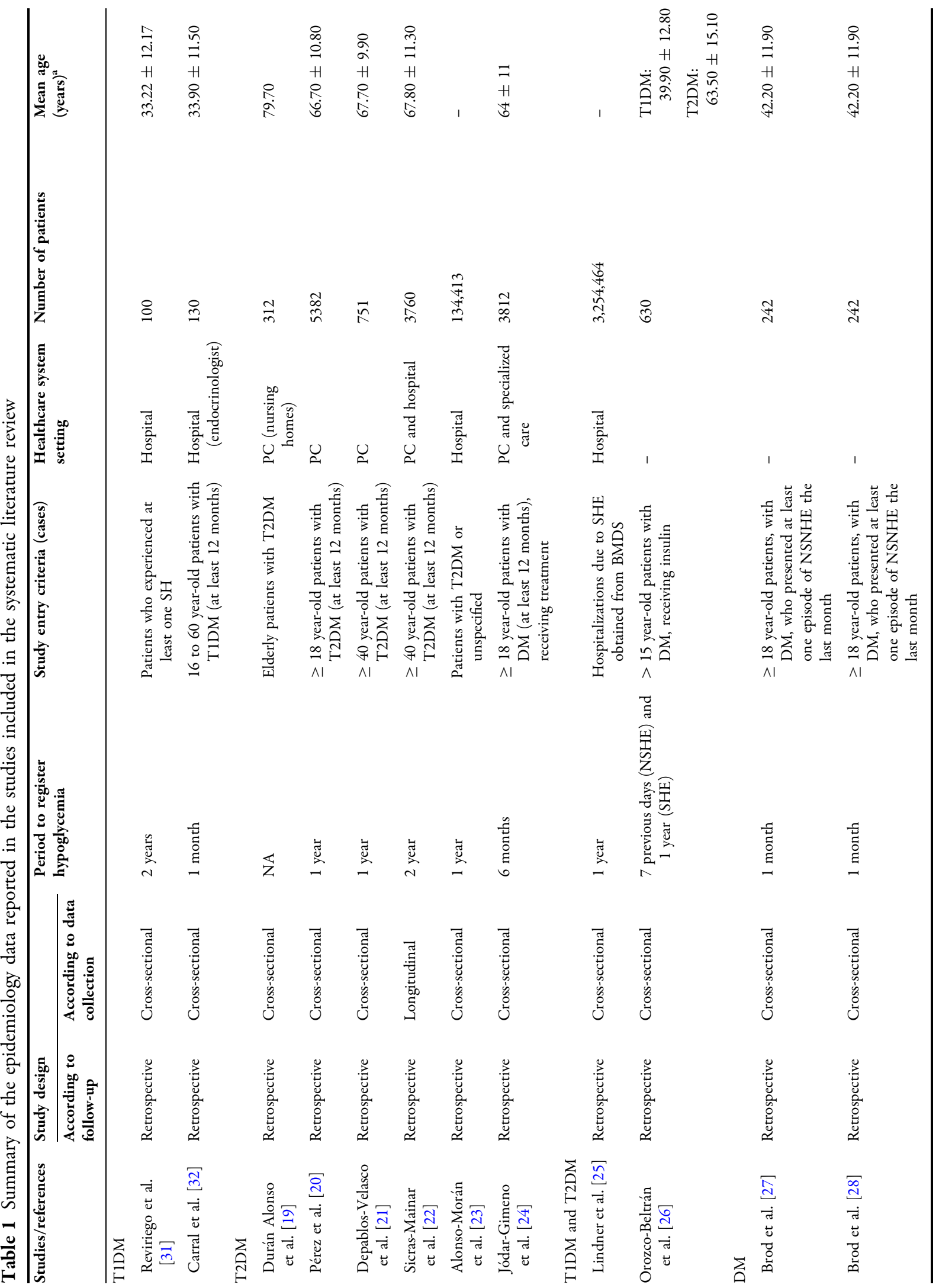




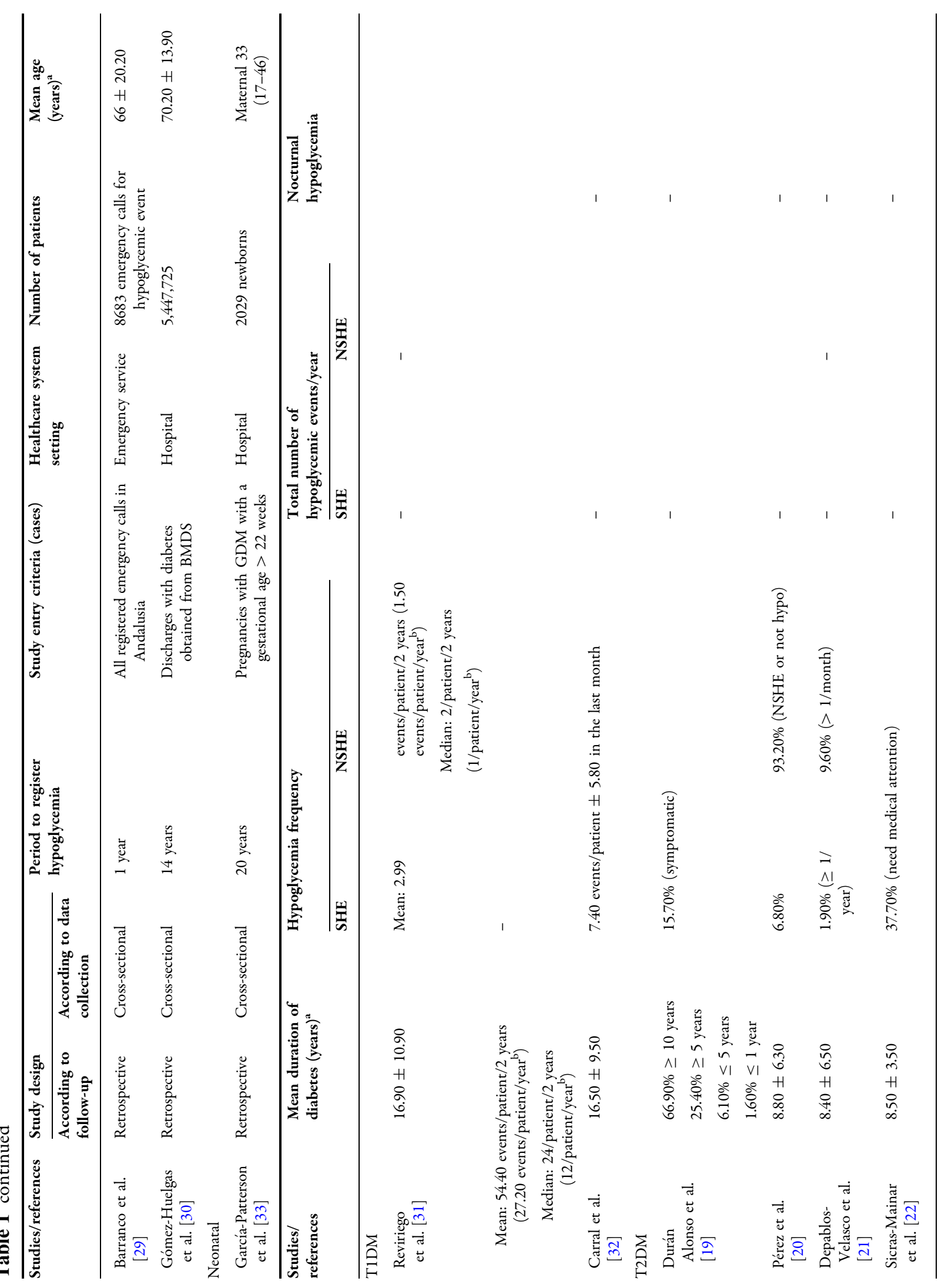




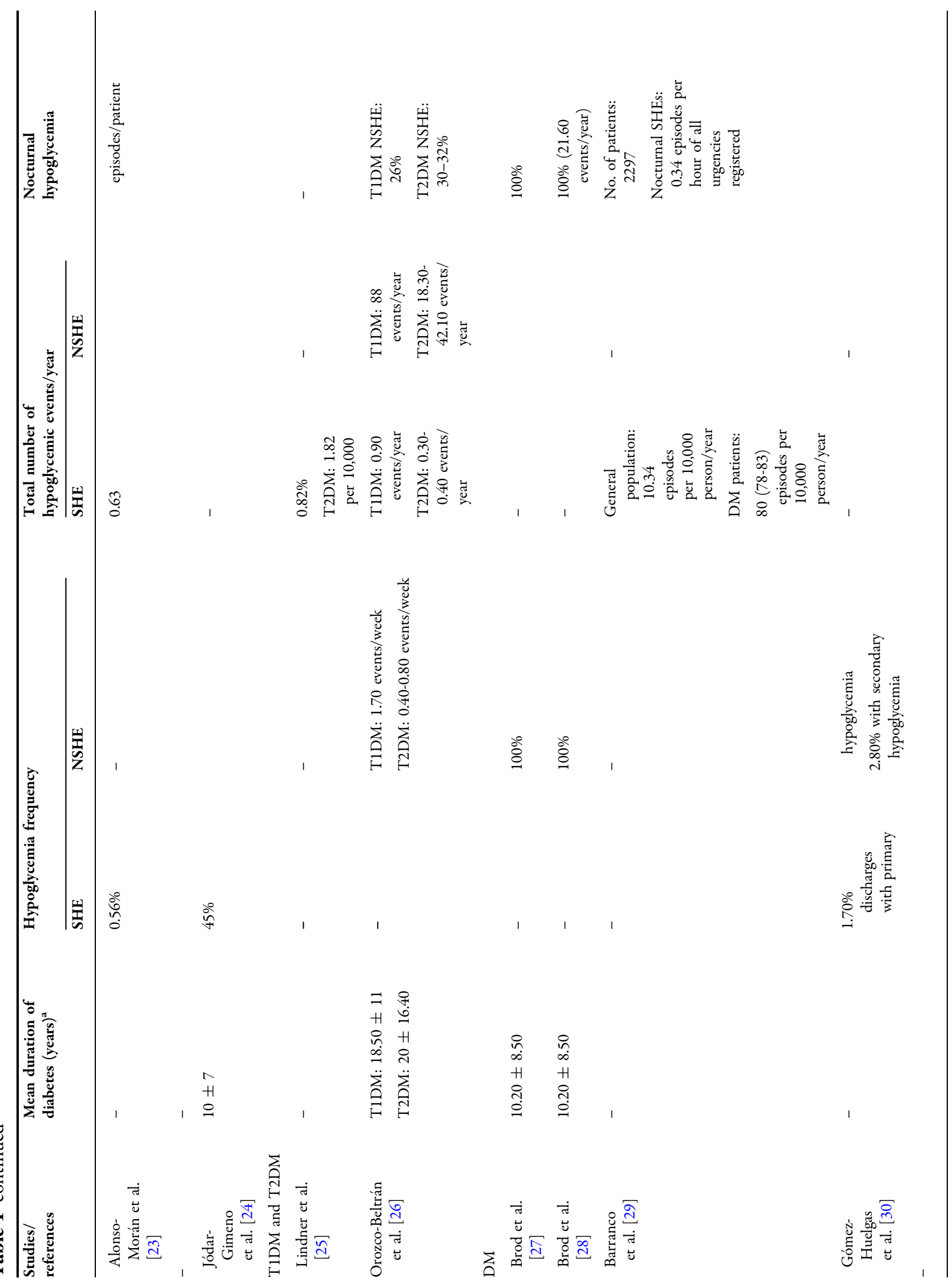




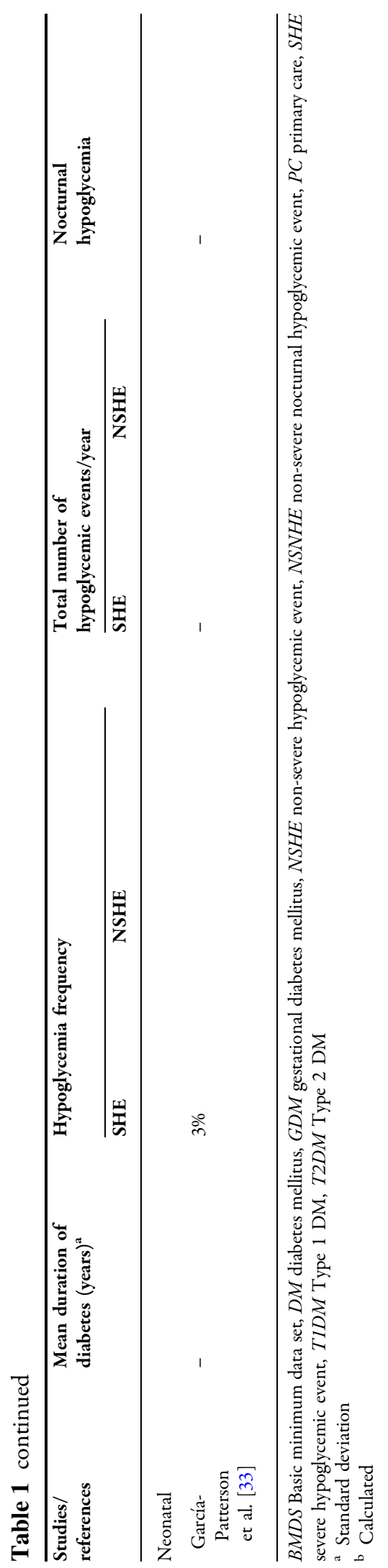

\section{Resource Utilization and Costs}

Table 2 summarizes information on HRU and costs associated with hypoglycemia obtained in the SLR (11 articles involving 10 studies) [20, 22-31].

\section{Severe Hypoglycemia}

Sicras-Mainar et al. reported that $0.50 \%$ of patients with T2DM needed to be hospitalized, among whom $1.00 \%$ had to be treated in the specialized care departments, and $34.10 \%$ attended medical visits in primary care settings over a period of 2 years [22]. Lindler et al. reported that $6.34 \%$ and $5.01 \%$ of the patients with T1DM and T2DM, respectively, required hospitalization [25]. Orozco-Beltrán et al. reported that among the respondents with either T1DM or T2DM, 30\% required emergency hospital visits and 19\% were admitted to hospital because of their hypoglycemia [26].

In terms of costs associated with patients with T1DM, Reviriego et al. reported an overall mean cost per episode of $€ 409.97$, of which $65.40 \%$ were direct costs and $34.60 \%$ were indirect costs [31]. These authors found that the highest costs were due to hospitalization (€204.98 per episode), representing $50 \%$ of the total costs [31]. Alonso-Morán et al. provided data on patients with T2DM [23]. These authors observed that the average overall cost per patient with T2DM was higher in a patient who had experienced one or more hypoglycemic episodes than in a patient who did not experience any such episode. The results presented by these authors were differentiated by gender and were specifically related to primary care, prescriptions, specialized care, emergencies and hospitalizations [23]. Barranco et al. recorded an estimated mean direct cost of $€ 713.10$ per episode in patients with either T1DM or T2DM. These costs increased if the hypoglycemia was nocturnal or if it required emergency hospital care or caused loss of consciousness [29].

\section{Severe and Non-Severe Hypoglycemia}

In the study by Pérez et al., a total of $6.80 \%$ of patients with T2DM required medical attention in the preceding year, of whom 0.50 and $4.60 \%$ 


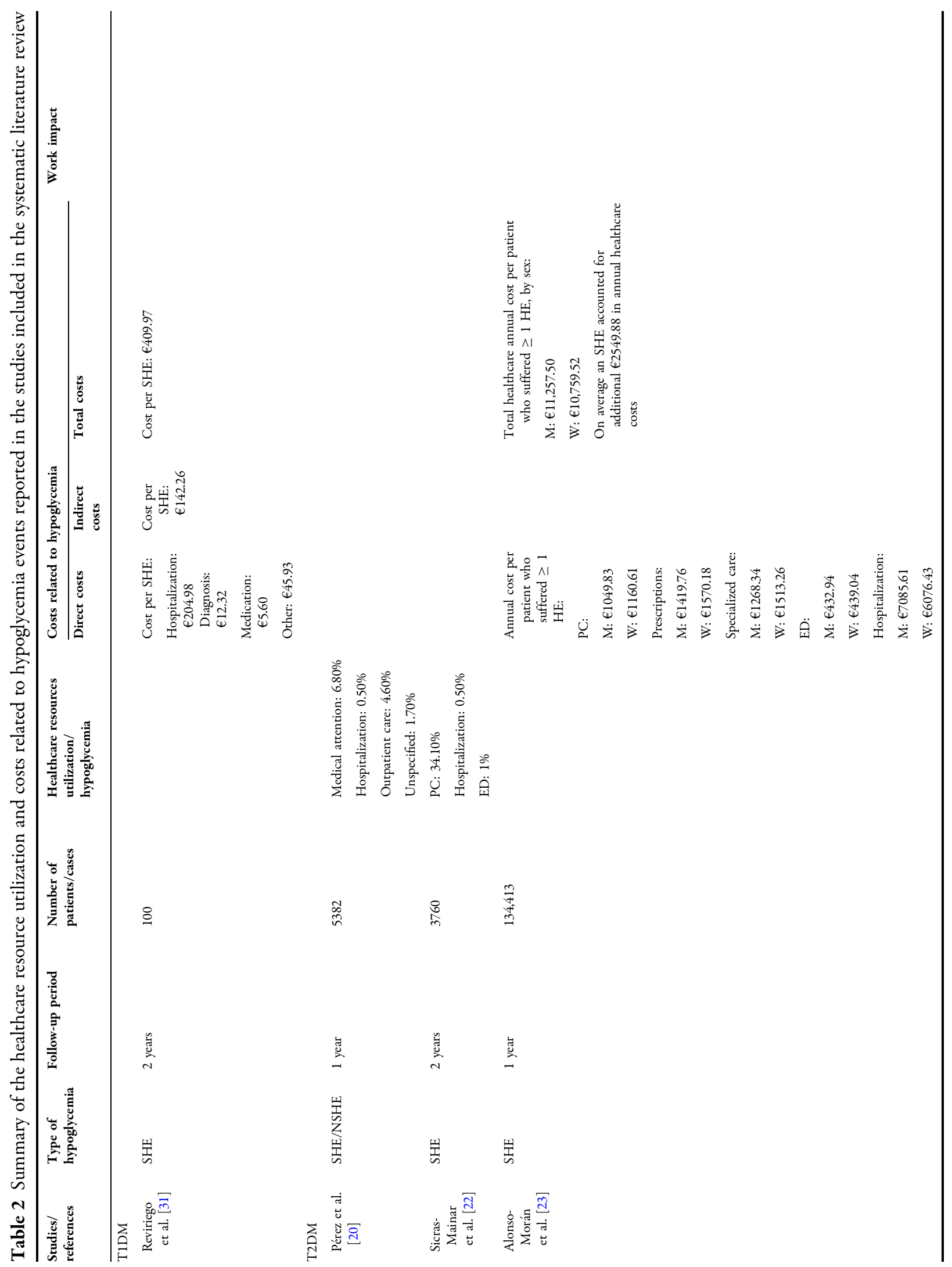




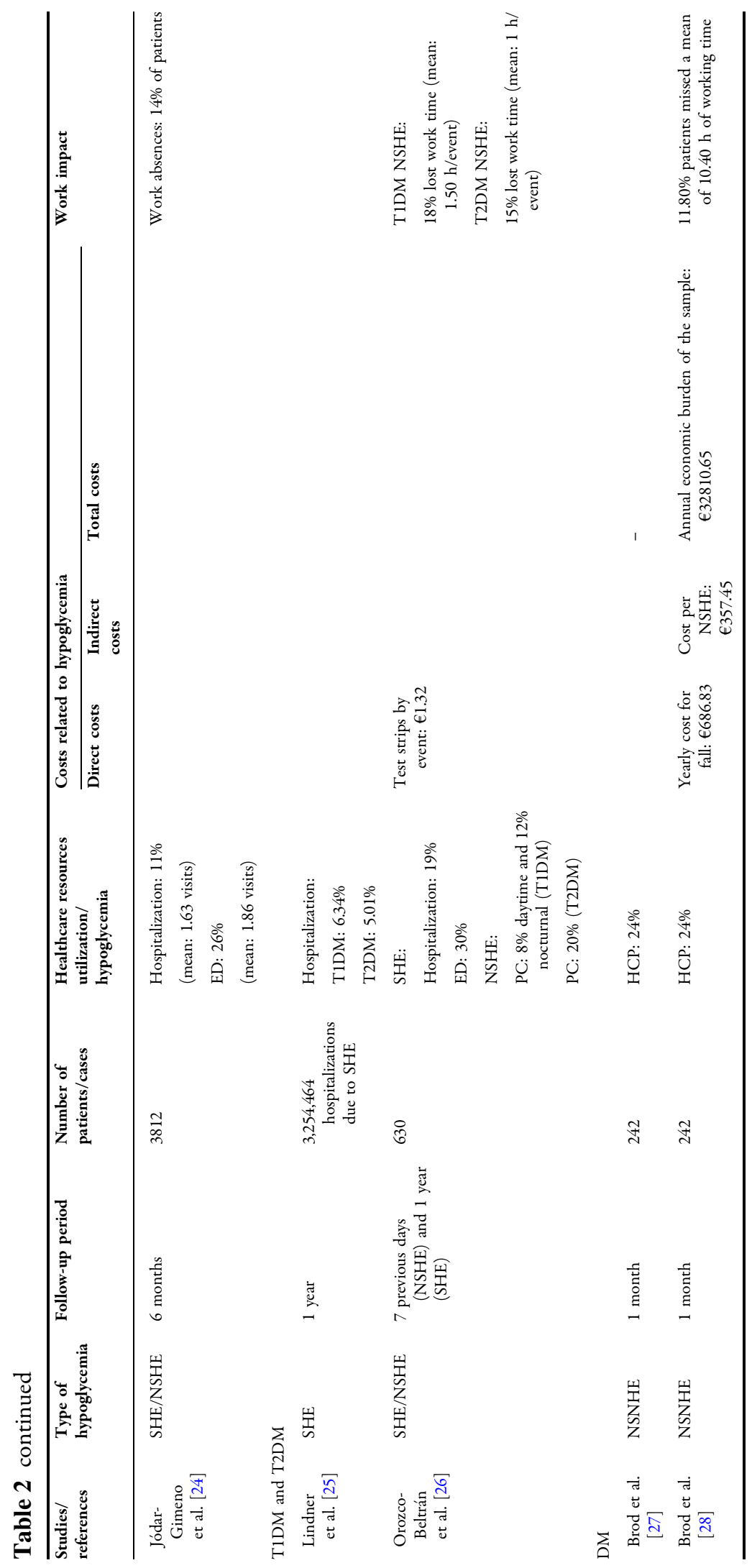




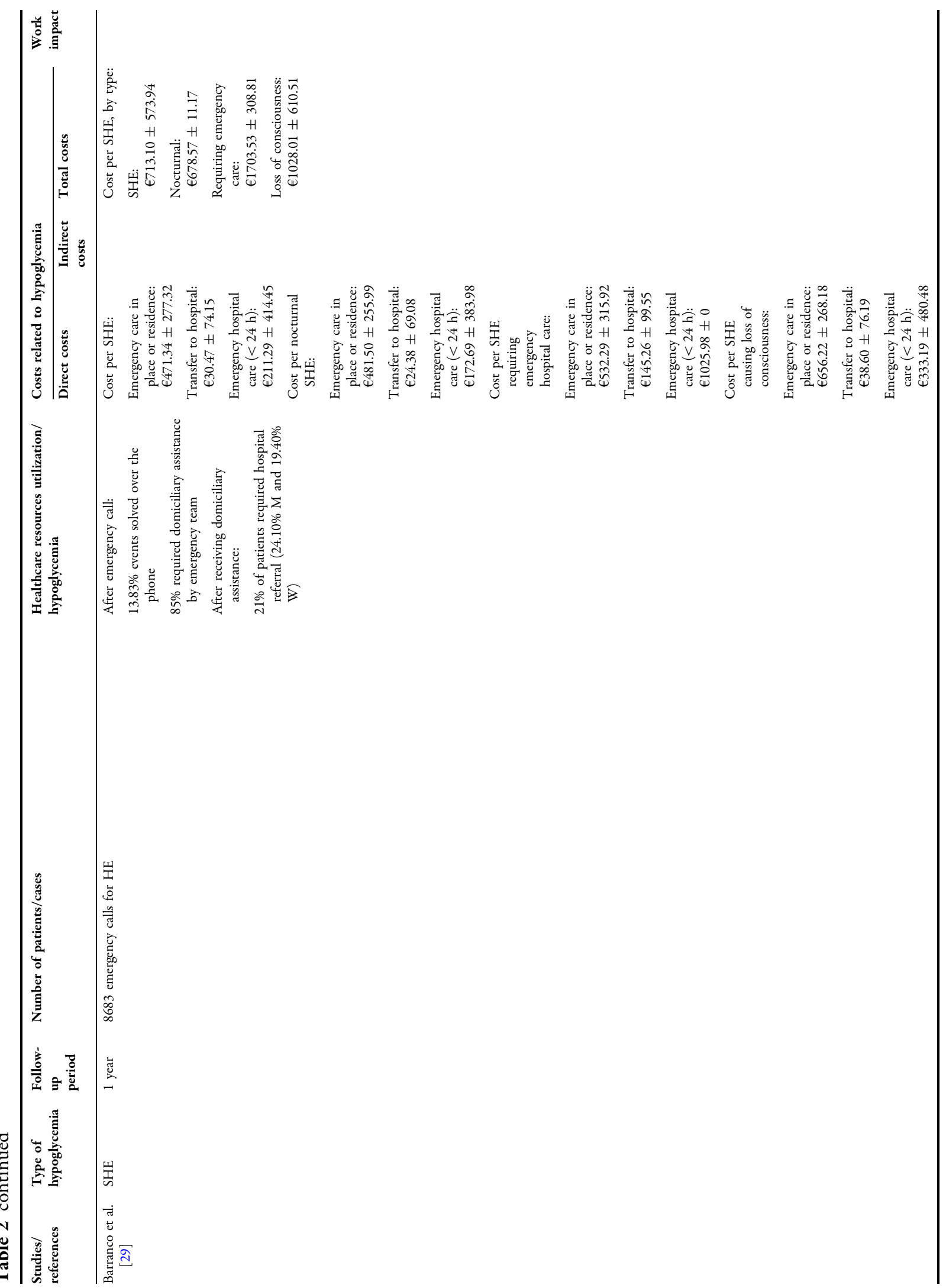




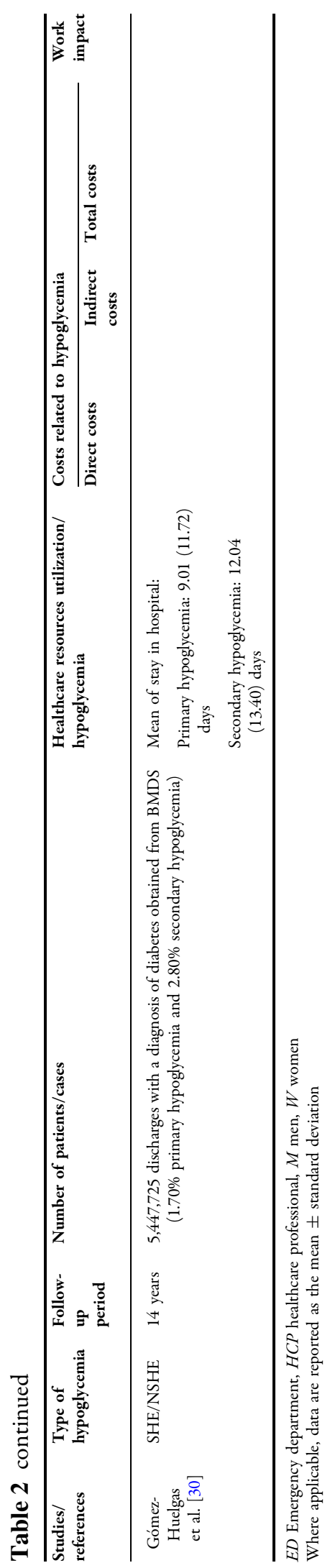

required hospitalization and outpatient care, respectively [20]. Jódar-Gimeno et al. reported that 11 and $26 \%$ of patients with T2DM required a mean of $1.63 \pm 1.34$ ( \pm standard deviation) hospitalizations and $1.86 \pm 1.32$ emergency department visits in the preceding 6 months [24].

\section{Impact at Work}

Analysis of the data on amount of working time lost revealed that among employed respondents with T1DM, 18\% of NSH events led to lost work time of approximately $1.50 \mathrm{~h}$ per event. In T2DM patients, $15 \%$ of NSH events led to lost work time of approximately $1 \mathrm{~h}$ per event [26]. Brod et al. showed that $11.80 \%$ of patients with DM experienced nocturnal NSH events that led to a mean of $10.40 \mathrm{~h}$ of lost work time per month [28].

\section{Quality of Life}

The QoL and fear of hypoglycemia data obtained in two studies $[21,24]$ through the use of validated questionnaires are shown in Table 3. The authors of these studies assessed data only from patients with T2DM who experienced both $\mathrm{SH}$ and $\mathrm{NSH}$.

In a study by Depablos-Velasco et al., patients with at least one $\mathrm{SH}$ or more than one NSH per month in the past year had a poorer QoL than did patients with no such events, as concluded from the results obtained from the Audit of Diabetes-Dependent QoL (ADDQoL) questionnaire [21]. No statistical significance was reached in the treatment satisfaction results obtained from the Diabetes Treatment Satisfaction Questionnaire (DTSQ). However, a significantly greater fear of hypoglycemia was observed for both groups of patients, those with at least one $\mathrm{SH}$ and those with one or more than one NSH per month in the past year, than for patients with no such events (results from the Hypoglycemia Fear Survey [HFS-II]) [21]. JódarGimeno et al. showed that patients with hypoglycemia expressed a higher fear for hypoglycemia than those who did not experience hypoglycemia; the difference was statistically significant (results from HFS-II), and the overall 


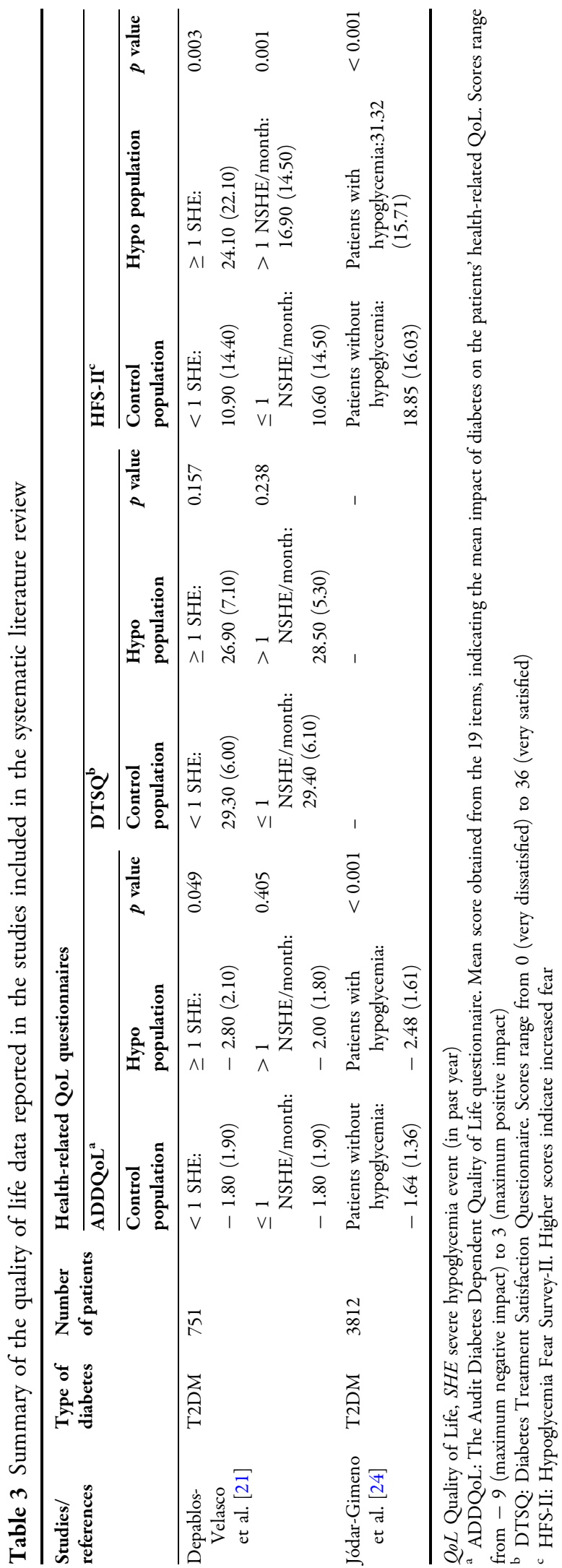

impact on their QoL was more negative in this population $(p<0.001$ [results from the ADDQoL]) [24].

\section{DISCUSSION}

This SLR provides an overview of the burden of hypoglycemia in patients with DM in Spain based on data published in the literature in the last 10 years by reporting information on the rate of hypoglycemia and on its impact on HRU and costs, and patients' QoL. The search strategy was robust and focused on collecting extensive and elaborate data. However, due to the observational nature and heterogeneity of the included studies, further high-quality prospective studies are necessary to accurately establish the burden of hypoglycemia in patients with DM in Spain.

The quality of the studies was not evaluated because the majority of articles selected in the search were observational studies, with different designs and objectives, making it difficult to use any assessment tool. This difficulty is due to the fact that most questionnaires available in the literature have been designed for assessing the quality of observational studies, having been developed mainly for comparative research between specific types of design or different intervention arms, which was not the objective of this study [34-36].

The data collected in the search showed a wide heterogeneity, possibly due to the large variety in study design, participants' inclusion criteria, study period and strategy used to register hypoglycemia (such as percentage of the sample in a specific timeframe, rates of events per unit of time, etc.), in addition to a lack of consensus in the definition of hypoglycemia. This led to a large variation in the results that detailed the estimated burden and costs of hypoglycemia.

The data observed in our analysis seem to be comparable to the results of a recent structured literature review by Elliott et al. [37]. These authors identified hypoglycemic event rates in patients with T1DM and T2DM and categorized them according to the insulin regimen. In patients with T1DM, SH rates ranged from 0.70 
to 1.59 episodes per patient per year, and NSH rates ranged from 91.00 to 136.80 episodes per patient per year. In patients with T2DM, SH rates ranged from 0 to 0.20 episodes per year; further, NSH ranged from 0.22 to 38.90 episodes per year depending on the insulin regimen [37]. Although these data cannot be directly compared with the results of our analysis, we did observe some degree of similarity in the numbers extracted in our search and global figures reported by Elliott et al. [37]. We postulate that standardizing the definition of hypoglycemic measures could help in the systematic collection of information, thereby enabling comparison of burden of this complication across countries [38].

Additionally, hypoglycemia has been considered to cause significant consequences that depend on the severity and duration of the episodes. Hypoglycemia has been shown to result in cardiovascular [39] and cognitive impairment, as well as falls, fall-related fractures, among other events, in certain populations, such as pediatric and elderly populations $[40,41]$. Further, the cognitive impairment in these populations could worsen the development of functional cognition. On the other hand, cardiovascular impairment may worsen the morbidity associated with hypoglycemia and lead to increased mortality due to sudden death syndrome [30, 40]. Further, the importance of appropriately managing nocturnal hypoglycemia is well-known as poor management leads to increased costs and resources, fear, anxiety, poor QoL, and a number of potential clinical consequences, including convulsions and coma and even death [42]. It has been well documented that hypoglycemia may lead to emergencies and hospitalization, resulting in an increased economic burden on patients with DM. Differences in study designs, timeframe, health system setting, etc. have hampered the comparability of results between studies. We were unable to draw any meaningful comparisons in terms of hospitalization rate, direct and indirect costs in patients experiencing $\mathrm{SH}$ versus NSH due to the heterogeneity of the studies. However, these data are comparable with the results in the literature highlighting that the more severe the hypoglycemic events, the higher the associated costs and HRU and the worse the QoL. A recent study in Italy collected data on cases with an established diagnosis of hypoglycemia in emergency departments. The results demonstrated that $\mathrm{SH}$ in patients with DM contributes substantially to the economic burden on national healthcare systems [43]. Another study assessed the total annual, direct, and indirect cost of SH events in nine European countries, including Spain. This study, conducted in 2016, reported an annual total cost for single SH event of $€ 1076.05, € 209.28$ and $€ 0.46$ for hospital-treated, medical professionaltreated and family-treated SH events in Spain, which in terms of the whole population affected translates into $€ 32,339,530.58, € 19,513,354.64$ and $€ 94,856.70$, respectively [44]. Taking these figures into consideration, the prevention of hypoglycemia is essential in DM management programs given its impact on patients and on healthcare systems. Failure to account for these costs may underestimate management strategies that minimize hypoglycemia.

With reference to the QoL information obtained from our literature search, none of the studies reported data on patients with T1DM. Further, only two articles assessed the healthrelated QoL and treatment satisfaction in patients with T2DM. We infer that the reason for this lack of data may not be a lack of interest to measure this outcome in patients with T1DM but, rather, because we excluded studies from our SLR that presented hypoglycemia data associated with a specific drug or intervention [45]. Patients with T2DM who experienced hypoglycemia had a poorer QoL versus patients with no such events. Further, patients with hypoglycemia expressed a higher fear of hypoglycemia, and the overall impact on their QoL was more negative as previously reported [38].

In summary, our analysis of studies included in our SLR reinforces the high burden of hypoglycemia on patients with DM. However, we consider that existing data are too heterogeneous to provide any consistent understanding of hypoglycemia episodes. Further, all included studies had retrospective data, implying that the development of the evidence are faster and generally less expensive than in prospective studies. Nonetheless, these data can lead to an 
erroneous estimate of the real rate of hypoglycemic events due to a lack of systematic collection of events in medical records, with these events being more difficult to follow if they are NSH episodes. Another aspect to take into account is the definition of hypoglycemia in these articles, which varies across studies. The International Hypoglycemic Study Group has recently worked on the definition and classification of hypoglycemia and on the ways to attribute severity to an event. Such guidelines may help researchers to design future studies better [11].

To conclude, this study delineates hypoglycemia as a frequent acute complication of DM that presents a high clinical, personal and socioeconomic impact, and it provides information that could be useful to improve diabetes care in Spain. However, considering the heterogeneity of the methods used in the reviewed studies, we believe that in future studies and analyses there is a need to comprehend the evolution of hypoglycemia and to determine the factors that may influence and help focus the data obtained in this SLR in terms of epidemiology, HRU and patients' wellbeing in Spain.

\section{ACKNOWLEDGEMENTS}

Funding. Eli Lilly and Company sponsored this study and the publication of this article. All authors had full access to all of the data in this study and take complete responsibility for the integrity of the data and accuracy of the data analysis.

Medical Writing Assistance. Richi Taneja, an employee of Eli Lilly and Company, provided medical writing assistance in the preparation of this article.

Authorship. All named authors meet the International Committee of Medical Journal Editors (ICMJE) criteria for authorship for this article. All take responsibility for the integrity of the work as a whole, and have given their approval for this version to be published.
Disclosures. Mercedes Núñez is an employee of Eli Lilly and company and has no other conflicts of interest. Silvia Díaz is an employee of Eli Lilly and company and has no other conflicts of interest. Tatiana Dilla is an employee of Eli Lilly and company and has no other conflicts of interest. Jesús Reviriego is an employee of Eli Lilly and company and has no other conflicts of interest. Antonio Pérez has participated as a consultant for or has received lecture fees or travel reimbursement from Sanofi-Aventis, Esteve, GSK, Almirall, Novo Nordisk, Eli Lilly, MSD, Boehringer Ingelheim, Novartis, Menarini, Janssen and AstraZeneca.

Compliance with Ethics Guidelines. Ethical approval was not required since this article is based on previously conducted studies and did not involve experiments with animals or humans performed by any of the authors.

Data Availability. Data sharing is not applicable to this article as no datasets were generated or analyzed during the current study.

Open Access. This article is distributed under the terms of the Creative Commons Attribution-NonCommercial 4.0 International License (http://creativecommons.org/licenses/ by-nc/4.0/), which permits any noncommercial use, distribution, and reproduction in any medium, provided you give appropriate credit to the original author(s) and the source, provide a link to the Creative Commons license, and indicate if changes were made.

\section{REFERENCES}

1. Kharroubi AT, Darwish HM. Diabetes mellitus: the epidemic of the century. World J Diabetes. 2015;6:850-67.

2. International Diabetes Federation (IDF) IDF Diabetes Atlas 2017, eight edition. 2017. Available online: http://www.diabetesatlas.org/

3. Soriguer F, Goday A, Bosch-Comas A, et al. Prevalence of diabetes mellitus and impaired glucose regulation in Spain: the Diabetes Study. Diabetologia. 2012;55:88-93. 
4. Mezquita-Raya P, Reyes-Garcia R, Moreno-Perez O, et al. Position statement: hypoglycemia management in patients with diabetes mellitus. Diabetes Mellitus Working Group of the Spanish Society of Endocrinology and Nutrition. Endocrinol Nutr. 2013;60:517 e1-18.

5. Brito-Sanfiel M, Diago-Cabezudo J, Calderon A. Economic impact of hypoglycemia on healthcare in Spain. Expert Rev Pharmacoecon Outcomes Res. 2010;10:649-60.

6. Mata-Cases M, Casajuana M, Franch-Nadal J, et al. Direct medical costs attributable to type 2 diabetes mellitus: a population-based study in Catalonia, Spain. Eur J Health Econ. 2016;17:1001-10.

7. Nuno-Solinis R, Alonso-Moran E, Arteagoitia Axpe JM, Ezkurra Loiola P, Orueta JF, Gaztambide S. Healthcare costs of people with type 2 diabetes mellitus in the Basque Country (Spain). Endocrinol Nutr. 2016;63:543-50.

8. Lopez-Bastida J, Boronat M, Moreno JO, Schurer W. Costs, outcomes and challenges for diabetes care in Spain. Glob Health. 2013;9:17.

9. Forbes JM, Cooper ME. Mechanisms of diabetic complications. Physiol Rev. 2013;93:137-88.

10. Rubin RR, Peyrot M. Quality of life and diabetes. Diabetes Metab Res Rev. 1999;15:205-18.

11. American Diabetes Association. 6. Glycemic targets: standards of medical care in diabetes-2018. Diabetes Care. 2018;41:S55-64.

12. Towler DA, Havlin CE, Craft S, Cryer P. Mechanism of awareness of hypoglycemia. Perception of neurogenic (predominantly cholinergic) rather than neuroglycopenic symptoms. Diabetes. 1993;42:1791-8.

13. Bonds DE, Miller ME, Bergenstal RM, et al. The association between symptomatic, severe hypoglycaemia and mortality in type 2 diabetes: retrospective epidemiological analysis of the ACCORD study. BMJ. 2010;340:b4909.

14. Zoungas S, Patel A, Chalmers J, et al. Severe hypoglycemia and risks of vascular events and death. N Engl J Med. 2010;363:1410-8.

15. Pieber TR, Marso SP, McGuire DK, et al. DEVOTE 3: temporal relationships between severe hypoglycaemia, cardiovascular outcomes and mortality. Diabetologia. 2018;61:58-65.

16. Amiel SA, Dixon T, Mann R, Jameson K. Hypoglycaemia in type 2 diabetes. Diabet Med. 2008;25:245-54.
17. Marrett E, Radican L, Davies MJ, Zhang Q. Assessment of severity and frequency of self-reported hypoglycemia on quality of life in patients with type 2 diabetes treated with oral antihyperglycemic agents: a survey study. BMC Res Notes. 2011;4:251.

18. International Monetary Fund. World economic outlook database. https://www.imf.org/external/ index.htm. Accessed 20 Apr 2016.

19. Durán Alonso JC, investigadores del estudio Diagerca. [Prevalence of diabetes mellitus in geriatric patients in nursing homes of Cadiz. Diagerca study]. Rev Esp Geriatr Gerontol. 2012;47:114-8 (in Spanish).

20. Pérez A, Mediavilla JJ, Minambres I, Gonzalez-Segura D. Glycemic control in patients with type 2 diabetes mellitus in Spain. Rev Clin Esp. 2014;214:429-36.

21. Depablos-Velasco P, Salguero-Chaves E, Mata-Poyo J, Derivas-Otero B, Garcia-Sanchez R, Viguera-Ester P. Quality of life and satisfaction with treatment in subjects with type 2 diabetes: results in Spain of the PANORAMA study. Endocrinol Nutr. 2014;61:18-26.

22. Sicras-Mainar A, Navarro-Artieda R, Ibanez-Nolla J. Clinical and economic characteristics associated with type 2 diabetes. Rev Clin Esp (Barc). 2014;214:121-30.

23. Alonso-Moran E, Orueta JF, Nuno-Solinis R. Incidence of severe hypoglycaemic episodes in patients with type 2 diabetes in the Basque country: impact on healthcare costs. BMC Health Serv Res. 2015;15:207.

24. Jódar-Gimeno E, Alvarez-Guisasola F, Avila-Lachica L, Palomares-Ortega R, Roldan-Suarez C, LizanTudela L. Quality of life and fear for hypoglycaemia in patients with type 2 diabetes mellitus. Rev Clin Esp. 2015;215:91-7.

25. Lindner L, Garcia-Sanchez R, Alvarez C, Betegon L, Badia X. Hospitalizations due to severe hypoglycemia in patients with diabetes mellitus in Spain. Rev Clin Esp (Barc). 2013;213:370-6.

26. Orozco-Beltrán D, Mezquita-Raya P, Ramirez de Arellano A, Galan M. Self-reported frequency and impact of hypoglycemic events in Spain. Diabetes Ther. 2014;5:155-68.

27. Brod M, Wolden M, Christensen T, Bushnell DM. A nine country study of the burden of non-severe nocturnal hypoglycaemic events on diabetes management and daily function. Diabetes Obes Metab. 2013;15:546-57. 
28. Brod M, Wolden M, Christensen T, Bushnell DM. Understanding the economic burden of nonsevere nocturnal hypoglycemic events: impact on work productivity, disease management, and resource utilization. Value Health. 2013;16:1140-9.

29. Barranco RJ, Gomez-Peralta F, Abreu C, et al. Incidence and care-related costs of severe hypoglycaemia requiring emergency treatment in Andalusia (Spain): the PAUEPAD project. Diabet Med. 2015;32:1520-6.

30. Gómez-Huelgas R, Guijarro-Merino R, Zapatero A, et al. The frequency and impact of hypoglycemia among hospitalized patients with diabetes: a population-based study. J Diabetes Complic. 2015;29:1050-5.

31. Reviriego J, Gomis R, Maranes JP, Ricart W, Hudson P, Sacristan JA. Cost of severe hypoglycaemia in patients with type 1 diabetes in Spain and the cost-effectiveness of insulin lispro compared with regular human insulin in preventing severe hypoglycaemia. Int $\mathrm{J}$ Clin Pract. 2008;62:1026-32.

32. San Laureano FC, Gutiérrez Manzanedo JV, Ayala Ortega C, Aguilar Diosdado M. Which variables are associated with a good metabolic control in patients with type 1 diabetes? Av Diabetol. 2013;29:68-73.

33. Garcia-Patterson A, Aulinas A, Maria MA, et al. Maternal body mass index is a predictor of neonatal hypoglycemia in gestational diabetes mellitus. J Clin Endocrinol Metab. 2012;97:1623-8.

34. Berger ML, Dreyer N, Anderson F, Towse A, Sedrakyan A, Normand SL. Prospective observational studies to assess comparative effectiveness: the ISPOR good research practices task force report. Value Health. 2012;15:217-30.

35. Berger ML, Mamdani M, Atkins D, Johnson ML. Good research practices for comparative effectiveness research: defining, reporting and interpreting nonrandomized studies of treatment effects using secondary data sources: the ISPOR Good Research Practices for Retrospective Database Analysis Task Force Report-Part I. Value Health. 2009;12: 1044-52.
36. Vandenbroucke JP, von Elm E, Altman DG, et al. Strengthening the Reporting of Observational Studies in Epidemiology (STROBE): explanation and elaboration. Epidemiology. 2007;18:805-35.

37. Elliott L, Fidler C, Ditchfield A, Stissing T. Hypoglycemia event rates: a comparison between realworld data and randomized controlled trial populations in insulin-treated diabetes. Diabetes Ther. 2016;7:45-60.

38. Khunti K, Alsifri S, Aronson R, et al. Rates and predictors of hypoglycaemia in 27585 people from 24 countries with insulin-treated type 1 and type 2 diabetes: the global HAT study. Diabetes Obes Metab. 2016;18:907-15.

39. Davis IC, Ahmadizadeh I, Randell J, Younk L, Davis SN. Understanding the impact of hypoglycemia on the cardiovascular system. Expert Rev Endocrinol Metab. 2017;12:21-33.

40. Schwartz DD, Wasserman R, Powell PW, Axelrad ME. Neurocognitive outcomes in pediatric diabetes: a developmental perspective. Curr Diab Rep. $2014 ; 14: 533$.

41. Sircar M, Bhatia A, Munshi M. Review of hypoglycemia in the older adult: clinical implications and management. Can J Diabetes. 2016;40:66-72.

42. Edelman SV, Blose JS. The impact of nocturnal hypoglycemia on clinical and cost-related issues in patients with type 1 and type 2 diabetes. Diabetes Educ. 2014;40:269-79.

43. Veronese G, Marchesini G, Forlani G, et al. Costs associated with emergency care and hospitalization for severe hypoglycemia. Nutr Metab Cardiovasc Dis. 2016;26:345-51.

44. Jakubczyk M, Lipka I, Paweska J, et al. Cost of severe hypoglycaemia in nine European countries. J Med Econ. 2016;19:973-82.

45. Lecumberri E, Ortega M, Iturregui M, Quesada JA, Vazquez C, Orozco D. Quality-of-life and treatment satisfaction in actual clinical practice of patients with type 1 diabetes mellitus (T1DM) and hypoglycemia treated with insulin degludec. Curr Med Res Opin. 2018;34:1053-9. 